\title{
Kıl Dokuma ile Kültürel Mirası Geleceğe Aktarmak Üzerine Deneysel Bir Çalışma
}

\author{
Öğr. Gör. Lütfiye Gül Gündüz ${ }^{1 *}$ \\ Prof. Günay Atalayer ${ }^{2}$
}

Gelis tarihi: 12.02 .2019

Kabul tarihi: 23.03.2019

\section{Atuf bilgisi:}

Uluslararası Bilimsel

Araştırmalar Dergisi (IBAD)

Cilt: 4 Sayı: 2

Sayfa: 322-332 Yıl: 2019

Dönem: Yaz

This article was checked by Turnitin Similarity Index $12 \%$

1 T.C. İstanbul Şişli Meslek Yüksekokulu, Türkiye, lutfiyegul.gunduz@,sisli.edu.tr, ORCID ID: 0000-0003-2827-7063

${ }^{2}$ Marmara Üniversitesi Güzel Sanatlar Fakültesi, Türkiye,

gunayatalayer@hotmail.com,

ORCID ID: 0000-0002-0566-1161

* Sorumlu yazar

\section{öz}

Anadolu'da unutulmaya yüz tutmuş ve deneysel çalışmaya konu olan geleneksel dokumalar Anadolu'nun beş değişik yöresinden seçilmiş kültürel ürünleridir. Bunlar; Siirt'te şal-şepik, Aydın'da kıl dokuma, Bursa'da elmalı öncek, Bayburt'ta ehram(ihram), Kastamonu'da Tosya Kuşağı adı ile bilinen yöresel olarak gerek yaşam alanlarında gerekse giyim amaçlı kullanılan özgün dokumalardır.

İnceleme yapılan bu geleneksel örneklerin, hammaddesi keçinin üst ve alt ipliklerinden eğrilmiş ve bazılarında yün karışımıyla üretilmiş olan ipliklerdir. Lifler kırkım kılı ve tabak kılı olarak iki şekilde temin edilmektedir. Yapısal durumuna göre çıkrık veya kirmanla elde büküm işlemi yapılmaktadır. El tezgahlarında dokunan bu kumaşlar, dokumacılarının ifadesiyle; "lifler yağışlı havalarda şişerek suyu içeri almaz ve soğuk geçirmezler. Sicak havalarda ise gözenekleri kapanarak hava sirkülasyonu sağlar.” Buna doğal bir yalıtım özelliği vardır diyebiliriz. Bu nedenle geleneksel dokumaları önemli kılan ana özellik; kıl ve tiftik ipliklerin yapisal durumudur.

“Anadolu'da Keçi K1lı|Tiftik Dokumalar Ve Ekose Desen Önerilerinin Analizi” adlı tez çalışmasına konu olan araştırma; analizleri yapılarak güncel kullanıma uygun tasarlanmış ve kültürel miras olarak aktarılması amaçlanmış olan; değişik örneklerin hammaddelerinin ve dokuma yapılarının incelenmesini kapsamaktadır.

$\mathrm{Bu}$ çalışmada hammaddenin özelliklerini değerlendiren yeni dokuma ürünlerini araştıran ürün geliştirme ve istihdam yaratma amacı çerçevesinde yorumlanan tasarım projeleri önerisi değerlendirilecektir. Çalışma, bu somut öneri ve görsel örnekleri kapsamaktadır.

Anahtar Kelimeler: Dokuma, Tiftik, Keçi Kı11, Anadolu. 


\title{
An Experimental Study to Transfer Cultural Heritage into Future
}

\author{
Öğr. Gör. Lütfiye Gül Gündüz ${ }^{1^{*}}$ \\ Prof. Günay Atalayer ${ }^{2}$
}

First received: 12.02 .2019

Accepted: 23.03.2019

\section{Citation:}

Journal of the International Scientific Research (IBAD)

Volume: 4 Issue: 2

Pages: $322-332$ Year: 2019

Session: Summer

This article was checked by Turnitin. Similarity Index 12\%

1 T.C. İstanbul Sișli Vocational Highschool, Turkey, lutfiyegul.gunduz@,sisli.edu.tr

ORCID ID: 0000-0003-2827-7063

${ }^{2}$ Marmara University, Faculty of Fine Arts, Turkey,

gunayatalayer@hotmail.com, ORCID ID: 0000-0002-0566-1161

* Corresponding Author

\begin{abstract}
The mostly bygone and forgotten traditional woven textiles constituting the subject matter of experimental study; are cultural products selected from five different regions of Anatolia. These fabrics known as "şal-şepik" in Siirt, "goat hair weaving" (k1l dokuma) in Aydın, "elmalı öncek" in Bursa, "ehram" in Bayburt, "Tosya belt" in Kastamonu, are alllocally original and unique woven textiles which are utilized either in general living spaces or as garments.
\end{abstract}

Raw materials used in these traditional fabrics are yarns spun from bottom and top yarn sof goat and in some cases, yarns made up of wool combinations. Fibers are supplied in two ways; as yearling wool and fellmongered wool. Due to material's structural state, a process of hand-spinning with a spinning wheel or a special type of drop spindle called "kirman" is applied. The fibers of these fabrics woven with hand looms "water resistant in rainy weather conditions and are cold-proof. Their pores shrink in size in hot weather facilitating circulation as well." In other words, these fibers in corporatea natural isolation property. For this reason; the main characteristic that makes these traditional fabrics important is the structural state of wool, angora goat hair and mohair yarns.

The research constituting the subject matter to the graduate dissertation study titled "Double Sheath/Textile Weaving in Anatolia and Chequer Pattern Recommendations" includes the analyses of raw materials and weaving structures of various fabric samples which are designed for modern daily usage plus with an objective to be established as cultural heritage.

In this study, a proposal of design projects, which use the characteristics of raw material, researches new weaving products and is interpreted within the framework of product development and generating employment, is evaluated. This study comprises of this concrete proposal andof visual samples.

Key Words: Weaving, Angora Wool, Goat Hair, Anatolia. 


\section{GENEL BAKIŞ}

Çalışma Anadolu'nun farklı yörelerinde günümüzde yerel amaçlarla kullanılan geleneksel dokumalar üzerine yapılmış deneysel bir çalışmaya dayanmaktadır. Bu çalışma Siirt'te şal-şepik, Aydın'da kıl dokuma, Bursa'da elmalı öncek, Bayburt'ta ehram (ihram), Kastamonu'da Tosya kuşağı adı ile bilinen yöresel olarak gerek yaşam alanlarında gerekse giyim amaçlı kullanılan özgün dokumaları kapsamaktadır.

Aydın'ın Olukbaşı Köyü’nde günümüzde sürdürülen kıl dokumacılıkla, barınma ve yer yaygısı olarak kullanılan dokumalar üretilir. Kıl keçisinden elde edilen ipliklerle yapılan dokumada, dokuyucu tarafindan bir üst bir alt olarak ifade edilen literatürde bezayağı örgüsü olarak kabul edilen örgü kullanıldığ tespit edilmiştir.

Siirt'in Eruh ilçesinde dokunan şal-şepik (gej) ise keçinin ince alt liflerinden elde edilen yörede tiftik iplik adı verilen çözgülük ve atkılık iplik ile bezayağı örgüsü yöntemiyle dokunmaktadır. Yörede desenlendirme amaçlı farklı renklerdeki tiftik iplikler kullanılarak çizgili ya da kareli dokumalarda yapılmaktadır.

Bayburt'ta ehram (ihram) adı ile bilinen dış giyim olarak kullanılan dokumada, Siirt'teki gibi tiftik iplik kullanılmıştır. Yörede dokuma sırasında yöreye özgü adları bulunan kenar süsleriyle (bordur) ve zemin desenlendirme yapılan dokumalar, statüye göre değişiklik gösteren renkleri ile birbirinden ayrılmaktadır.

Bursa'da elmalı öncek olarak bilinen ve günümüzde yün iplikle yapılan dokumalar geçmişte tiftik karışımlı ipliklerle dokunup, korumalı kumaş boyama (bağlama batik) tekniği kullanılarak desenlendirme yapıldığı gözlemlenmiştir.

Kastamonu'da yörenin bir ilçesi olan Tosya'da üretilen Tosya kuşağı tiftik iplik kullanılarak dokunmuş, diğer yörelerden farklı olarak $3 \backslash 1$ dimi örgüsü ile dokuma yapıldığı tespit edilmiştir.

İncelenen bu dokumalar Aydın Olukbaşı'ndaki ve Bayburt'taki örnekler dışında eni 20-35 cm olan dar dokumalardır. Dokuma genelde bezayağı örgüsü ile yapılmakta ve yörelere göre desenlendirmeler değişmektedir. Keçinin doğal kıl renginin kullanımının yanı sıra Siirt’te ipliği boyama ile farklı renklerde de üretim mevcuttur. Ayrıca Keles'te geleneksel olarak kullanılan toprak boya adı verilen ve günümüzde toz boya diye adlandırılan kimyasal boyalarla siyah boyama yapılmaktadır (Durak, 2015).

\section{LIFIN YAPISAL ÖZELLIKKLERI}

"Kıl dokumacıllı̆ında hammaddenin elde edildiği kıl keçileri ilk evcilleştirilen hayvan türlerinden kabul edilmektedir. Değişik çevre şartlarına uyum sağlayan kl keçileri diğer yün liflerinden farklı özellikler göstermektedir (Gezer, 2005)."

"Yün liflerinin fiziki özelliklerinin başında lif inceliği ve uzunluğu gibi lifin kalitesini belirleyen özellikler yer alır. Genel olarak liflerin tanımlanmasinda dayanıklllk, uzama ve esneklik gibi özelliklerine bakılmaktadır (Harmancioğlu, 1947)."

Keçi kıllarına baktığımızda bu liflerin yapısında koyun yününden farklılıklar gösteren, özellikleri olduğunu belirtebiliriz. Bunlar; başta renk, parlak olmak üzere (lifin ayırıcı yapısını belirleyen) tuşesi ${ }^{1}$ tespit edilmektedir. Araştırmalarda keçi kılı lifinin üst ve alt lifler olarak ikiye ayrıldığı fark edilmektedir. "Alt lifler ince yumuşak tutumlu olup tiftik yapımında kullanilırken, üst lifler kaba sert olup kıl iplik elde edilmektedir. Yapılan araştırmada bunu gözlemlemek mümkün olmuş, ince alt lifler yörede iplik olarak kullanılmadı̆̆ ve isteyen üretim sahiplerine verildiği gözlemlenmiştir (Öztaban, 2013)."

Keçilerin üst kılları kaba ve kıvrımsızdır. Kıl keçilerinden elde edilen lifler, kaba, sert olduğundan kohezyon (birbirine bükülerek tutunma) yetenekleri düşüktür tek katlı iplik yapımında kullanılmazlar. Bunlar ancak çok katlı, kalın, kaba ip ve ipliklerin yapımına elverişlidir. Çadır, haba, çuval yapımında

\footnotetext{
1 Tuşe: Kelime anlamı olarak dokunuş, dokunum, dokunma işi veya biçimi ve temas anlamlarına gelmektedir. Tekstilde tuşe kelimesi ise kumaşlara dokunduğumuzda bize verdiği hissi anlatmak için kullanılır. / http://www.tekstildershanesi.com.tr
} 
kullanılan iplikler; iki lifi ayrı ayrı bükmekte ve daha sonra bu bükülmüş iki kılı bir arada tekrar bükmektedir. Bu nedenle "ipliklerin çift kat eğrilmekte" olduğu söylenir (Öztaban, 2013). Bu sert ve kalın iplikler bu yüzden kumaş dokumada kullanılmaz. Yer yaygısı ve mekân amaçlı çadır ve benzeri amaçlar için kullanılabilir.
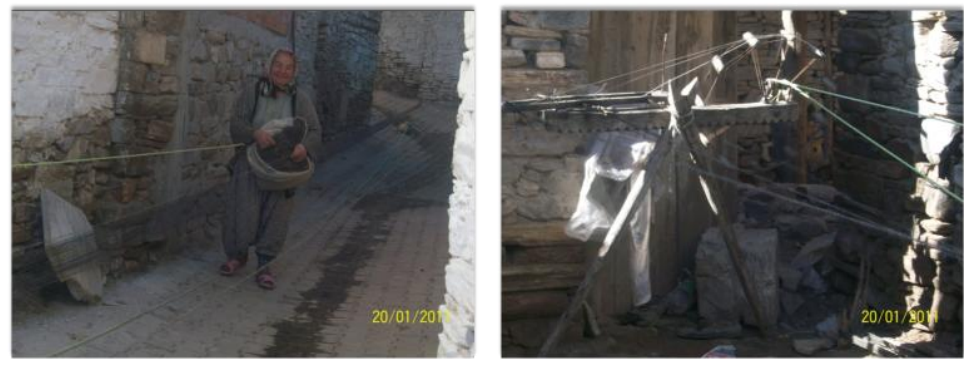

Fotoğraf: Mustafa Öztaban

Şal-şepik, ehram gibi giysi ya da dıș giyim aksesuarı olarak kullanılan tiftik ise, ince iplik halinde kirman ile eğirilmektedir. Giyim ve mekân için kullanılan tiftik, lifin özelliği ve eğrilmedeki özellikleri bakımından belirgin olarak farklıdır.

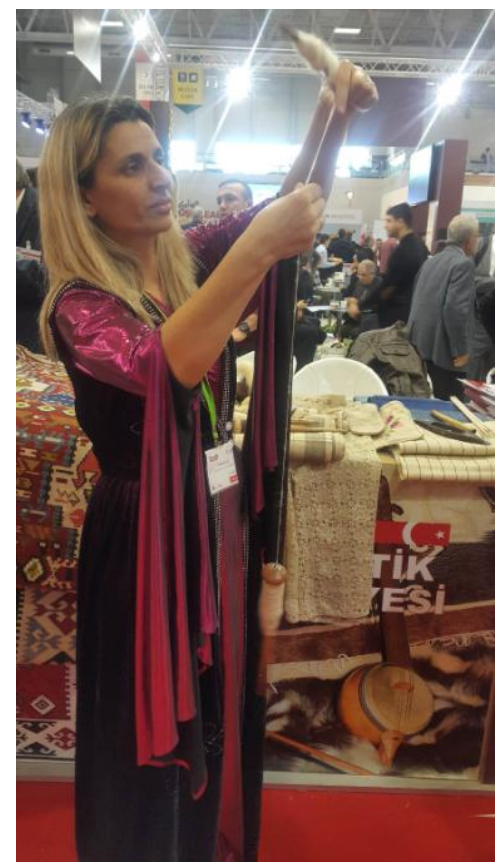

Fotoğraf: L. Gül Gündüz

"Genel olarak dağllk bölgelerde yetişen keçilerin kıllarının, ovada yetişen keçi killarından daha kalın, kaba ve sert" olduğu ve k1l keçisi liflerinin kalitesinde k1lın rengi, cinsi ve elde ediliş şeklinin etkili olduğu bilinmektedir (Harmancıŏlu, 1974). "Keçi kllları genellikle siyah renkli olmakla beraber aralarında beyaz, kahverengi, koyu gri ve sarımtırak renkleri de bulunabilir. Siyah keçi kulları içinde çeşitli nedenlerle diğer renkler de (beyaz, gri) bulunabilir. Bu çeşitli renkler kilda mevcut olan siyah renk pigmentlerinin değişik derecelerde açılmasından meydana gelmektedir (Harmancioğlu, 1974, s. 257)." Koyu siyah, çok parlak, kalın olan ve kırkım yolu ile elde edilen lifler birinci kalite olarak belirlenmektedir.

Farklı araştırmacılar tarafından fiziki ve kimyasal özellikleri bakımından incelenmiş olan keçi lifleri, her türlü iklim şartlarına elverişli olan kıl dokumaların hammaddesidir. Saf kıldan dokunan kıl çadır, haba, şal-şepik, tosya kuşağı, kıl liflerinin bilinen yapısal özelliklerine bağlı olarak teknik özelliklere sahiptir. Bu lifle yapılan çadırların, yanmazlık, yağmur geçirmezlik özelliği bilinmektedir. Ayrıca akrep, yılan 
gibi zehirli hayvanlar bu dokumalarla yapılmış zeminler üzerinde yürüyemediklerinden bu nedenle çadıra giremeyeceği görüşü ile tercih edilmektedir.

Dokunan ürünlerin bir diğer ortak özelliği de gözeneklerin iklim şartlarına göre genleşip daralarak hava sirkülasyonu sağlamasıdır. Bu nedenle insanları hem sıcaktan hem soğuktan koruyacağı geçmişten bugüne kadar deneme yanılma yöntemleri sayesinde doğruluğu tespit edilmesi ile tercih edilmektedir.

$\mathrm{Bu}$ liflerle yapılan dokumaların; yapılmış araştırma sonuçlarına göre bu özelliklerinin değişik kullanım alanlarında farklı biçimde değerlendirildiği görülmektedir. Kıl çuvallar, yem torbaları, çadır bezleri, heybe, çul, kilim dokumaları ve giyim eşyası olarak kullanıldı̆̆ı gözlendiğinde lifin kullanım özellikleri ortaya çıkmaktadır.

\section{Çizelge - 1 Ürün Farklılıkları (L. Gül Gündüz)}

\begin{tabular}{|c|c|}
\hline $\begin{array}{l}\text { Aydın-Bozdoğan/Kıl } \\
\text { Çadır }\end{array}$ & $\begin{array}{l}\text { Kıl çadırlar, doğal renkli düz siyah dokumalardır. Dokunan kumaş enleri } \\
40-100 \mathrm{~cm} \text { arasında olan } 6 \text { ile } 8 \text { parçadan oluşur. } \\
\text { Bezayağı dokunan parçaların tek süsleme ögesi birleştirilirken yine doğal } \\
\text { k1l ipliklerle birleştirilir. Yer yaygısı veya taşıma gereçleri olarak kullanılan } \\
\text { k1l dokumalar tek renk dokunmasının yanı sıra istenilen miktarda çözgü ve } \\
\text { atkıdan farklı renkteki kıl iplikle çizgili olarak desenlendirilmektedir. }\end{array}$ \\
\hline Siirt-Eruh/Şal Şepik & $\begin{array}{l}\text { Doğal renkte dokunan şal-şepik kumaşlarının yanı sıra farklı renklerde de } \\
\text { dokunan kumaşlar görülmektedir. Dokunan kumaşın eni } 30-35 \mathrm{~cm} \\
\text { arasındadır. Dar dokuma olarak tanımlanır. Bezayağ1 dokunan kumaşlar } \\
\text { yine farklı renklerdeki tiftik ipliklerle çizgili ya da kareli olarak da } \\
\text { dokunmaktadır. Yörede giysi olarak kullanılmaktadır. }\end{array}$ \\
\hline KastamonulTosya Kuşağı & $\begin{array}{l}\text { Saf krem rengi tiftik iplikle dokunan tosya kuşağı } 3 \backslash 1 \text { dimi örgüsüyle } \\
\text { kendinden desenlendirme yapılmaktadır. Kuşağı başlangıç ve bitiş } \\
\text { uçlarında farklı renk ve ipliklerle çizgi yapılarak desenlendirilmektedir. } \\
\text { Kuşağın eni } 25-35 \mathrm{~cm} \text { arasında boyu ise } 250-500 \mathrm{~cm} \text { uzunluğunda } \\
\text { dokunmaktadır. }\end{array}$ \\
\hline Bayburt/ Ehram & $\begin{array}{l}\text { Tiftik ve yün karışım ile el bükümü iplikler, krem, sütlü kahverengi ve } \\
\text { kahverengi renklerde dokunan ehram(ihram), bezayağ örgüsü ve dokuma } \\
\text { sırasında atkıdan kenar süslemesi (bordür) yapılan dokumalardır. Kanat } \\
\text { sözcüğü ile adlandırılan iki ayrı parça olarak dokunan bu kumaş daha } \\
\text { sonrasında özel el dikişi ile birleştirilmektedir. Eni } 85 \mathrm{~cm} \text { boyu ise } \\
250 \mathrm{~cm} \text { 'dir. }\end{array}$ \\
\hline $\begin{array}{c}\text { Bursa-Keles / Elmalı } \\
\text { Öncek }\end{array}$ & $\begin{array}{l}\text { Yün ve keçi k1lı karışımlı olan dokuma krem renktedir. Bezayağ örgüsü ile } \\
\text { dokunur. Eni } 20-25 \mathrm{~cm} \text { arasında boyu ise istenilen uzunlukta } \\
\text { dokunmaktadır. Dokuma işleminden sonra kapatılarak boyama işlemi } \\
\text { yapılan dokumalar, farklı renkte ve farklı kalitedeki iplikler ile } 3 \text { parça } \\
\text { şeklinde yanyana birleştirilmektedir (Literatürde bağlama batik olarak } \\
\text { bilinen boyama desenlendirme tekniği). }\end{array}$ \\
\hline
\end{tabular}




\section{YENI KULLANIM ALANLARI İÇIN TASARIM ÖRNEKLERİ}

\section{TASARIM ÖRNEKLERİ 1}

Anadolu'da üretilen ve kullanımı devam eden kıl \ haba dokumaların, aynı örgü ve renklerin kullanıldığı diğer geleneksel dokumalardan farklı ve özgün olma durumunun tamamen hammaddeye bağlı olduğunu söyleyebiliriz. Tasarımda özgünlüğün hammaddenin özelliğine bağlı olarak ortaya çıkarmak ve bu özelliğe dayanarak günümüz kullanımlarında yer alacak yeni tasarımlar önermek için lifi analiz ettiğimizde; bu dokumaların ayırt edici özelliğinin, kıl lifinin fiziki yapısından kaynaklandığını söyleyebiliriz.

$\mathrm{Bu}$ nedenle Anadolu'da kullanılan keçi kıllarından elde edilmiş doğal kıllar; çözgü ve atkıda kullanılırken, yeni ve çağdaş başka malzemelerle birlikte yaratıcı yeni bir ürün projesinde ele alınmıştır.

Bu proje ile yeni kullanım alanları oluşturularak keçi kıllarının yeni tasarımların malzemesi olabileceği gösterilmek istenmiş ve deneysel bir çalı̧̧ma yapılmıştır.

Söz konusu olan deneysel çalışma örneği İstanbul Halı İhracatçıları Birliği’ne tasarım uygulama önerisi olarak sunulmuş, 9.Halı Tasarım Yarışması kapsamında "MIRIZZZA" adı ile yer almıştır. Tasarımlarda kıl ipliğin farklı birim kullanımları ve örgü değerlendirmeleriyle ve bunların hacim yaratan görsel etkileri ile farklılıklar hedeflenmiştir. Buna bağlı olarak; tasarımlarda hem kıl ve hem de iki farklı hammaddeden üretilen iplikler ile çözgü hazırlanmış, renkli el eskizleri çizilmiş, beş farklı ürün görseli koleksiyon bütünlüğünde dokunarak bir prototip çalışması yapılmıştır.

Mırizza I'de grup hareketli, k1l iplik ve farklı hammadden olan diğer iplik ile birlikte hacimli bir görüntü elde edilirken, ikinci kat olarak yüzeyde pamuk çekirdek iplikli parlak ipliğin çözgü atlamaları yapmasıyla kıl ipliğin diğer iplik içerisinde hapsolmuş etkisi ve üç boyutlu doku yanılsaması oluşturulmuştur.

Mırizza 2'de k1l ipliğin etkisini kaybetmeden dişli bir görüntü ile diğer iki malzemenin arasında hapsedilmiş, bağlantı atkılarıyla katların yer değişimi sağlanarak, çift yüzlü bir dokuma planlanarak hacimli bir dokuma elde edilmiştir.

Mırizza 3' te ekose kumaş görünümünden yola çıkarak eşit karelemelerin dışında eşitsizlikle birlikte algıda illüzyon hissi veren, kare desenler uygulanarak, derinlik etkisi veren bir kumaş tasarım örneği 2ortaya çıkmıştır.

Mırizza 4'te ön ve arka yüzü aynı görsellikte olan dokumada k1l ipliğin yoğun olarak kullanılmas1 hedeflenmiştir. Bunun sonucunda tasarımda monotonluğu kırmak amacıyla pamuk çekirdekli parlak iplik ile hacim yaratılmış ve çift tarafı da aynı görsellikte kullanılabilecek bir dokuma yapılmıştır.

Mırizza 5' te k1l ipliğin etkisi azaltılmış, kumaşın üst yüzeyinde poliyamid ipliğin altına hapsolmuş kıl iplik yer yer üste alınmış, böylece hedeflenen üç boyutlu hacimli bir görsellik yaratılmış ve bu tasarım yarışma kapsamında bire bir uygulanan $130 \mathrm{~cm}$ x $220 \mathrm{~cm}$ örneği ile ödül töreninde sergilenerek yer almıştır. 


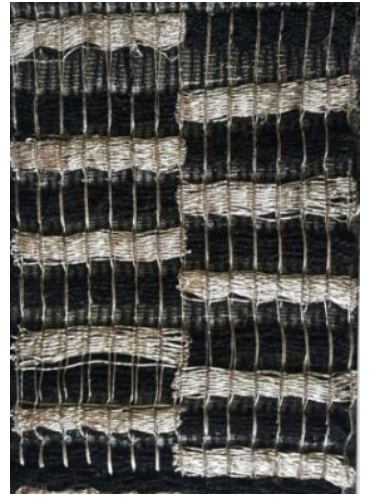

Şekil 1(Mırizza 1)

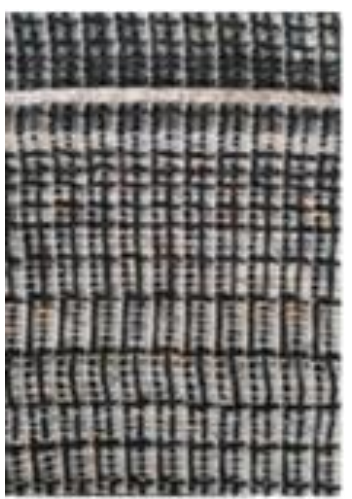

Şekil 3(Mırizza 3)

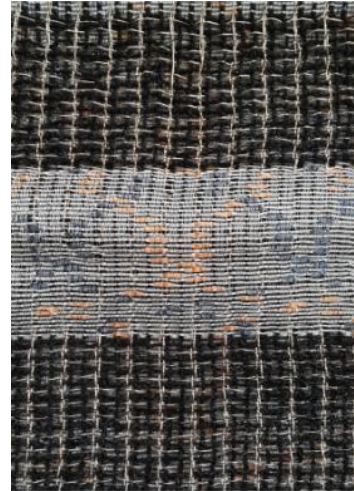

Şekil 2 (Mırizza 2)

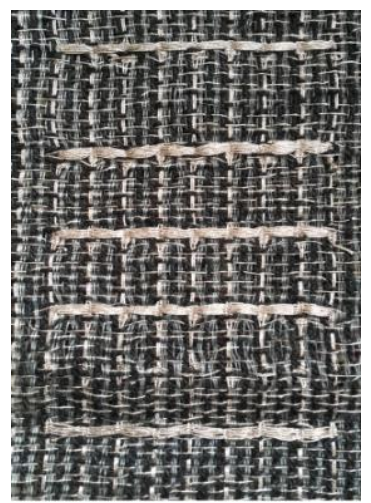

Şekil 4 (Mırizza 4)

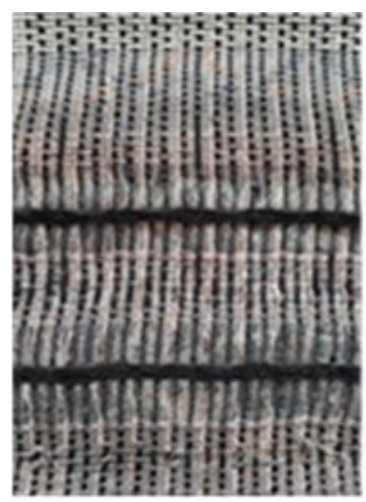

Şekil 5 (Mırizza 5)

Deneysel Tasarım Dokuma Örnekleri: L. Gül Gündüz 


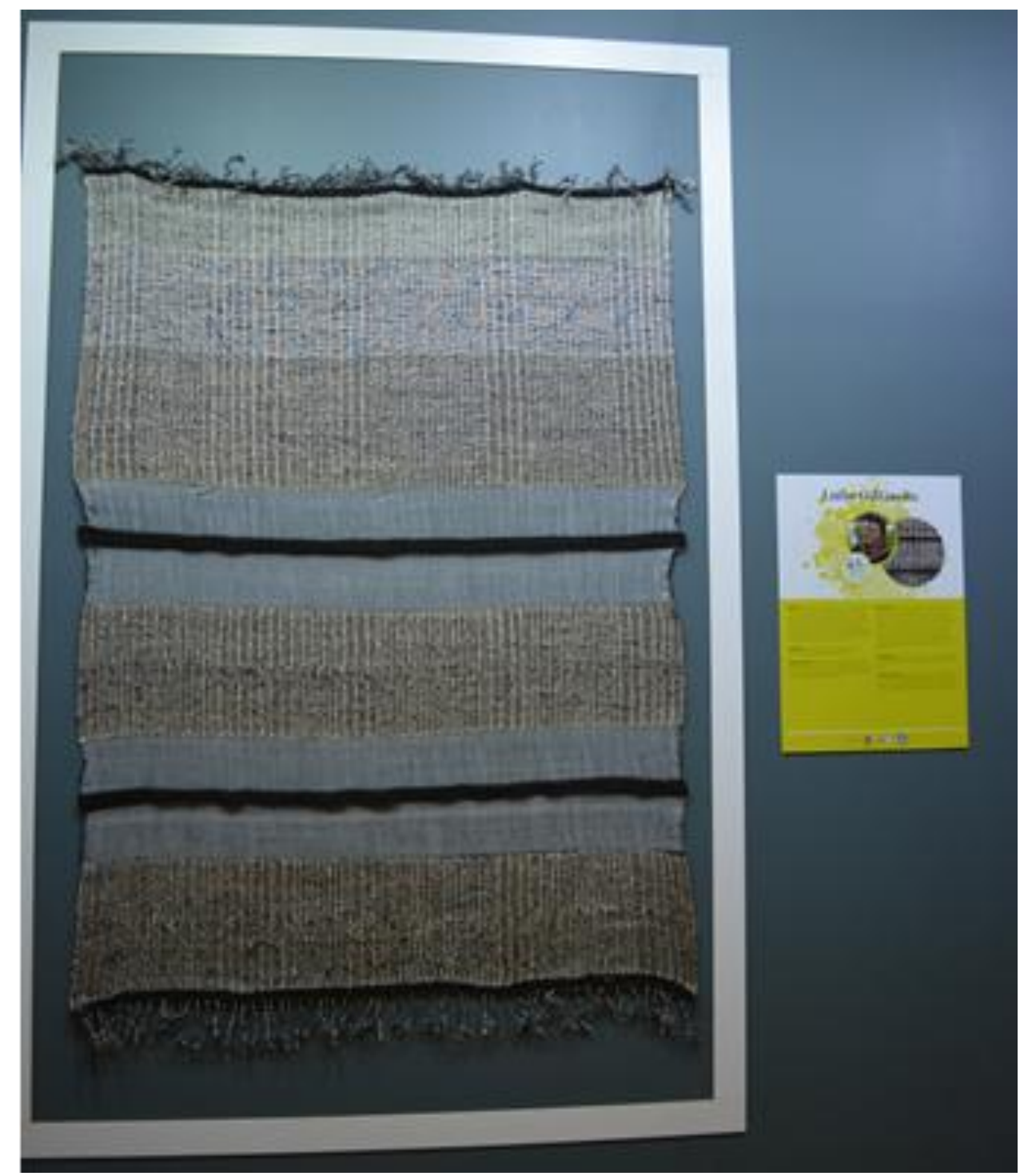

9.IHHIB HALI TASARIM YARIŞMASI Ödül Töreni

Tasarımc1: L. Gül Gündüz

\section{TASARIM ÖRNEKLERİ 2}

Yedinci Uluslararası Tekstil Kongresi, Anadolu'ya Dokunan Bezler "BEZCE 2016" etkinliğinde bir çalıştay gerçekleştirilmiş, yapılan çalıştay sürecinde, Anadolu'daki geleneksel tiftik dokuma ürünler birçok tekstil tasarımcısı tarafından giysi tasarımı için kullanılmıştır. Projede uygulama alanı, yelek ve çanta olarak saptanmış, tasarımlar farklı tasarımcılar tarafından ve özgün hikayeleri ile uygulanmıştır. $\mathrm{Bu}$ çalıştaydaki geleneksel kıl ve tiftik dokumalarla yapılmış yelek ve çanta tasarımları ile geleneksel dokumaların güncel ve yeni bir tasarım nesnesi oluşumunda nasıl yer alabileceği örneklenmiştir.

\section{Örnek:1}

Bursa Keles'te dokunan elmalı öncek adı verilen geleneksel dokumanın Anadolu'da kullanımı giysi üzerine önlük ve arkalık (elmalı önceklartlık) olarak bağlanması şeklindedir. Çalıştayda keles bezi, tekstil tasarımcı tarafindan yelek ve çanta tasarımıyla güncel yaşamda kullanılabilecek bir ürün örneği olmuştur. ${ }^{2}$

\footnotetext{
${ }^{2}$ Marmara Üniversitesi G.S.E. Öğrencisi, Gözel, Cihan.
} 


\section{Örnek:2}

Yine aynı proje kapsamında Bayburt ehramı(ihram) başka bir tasarımcı tarafindan dokumanın sert, biçim alabilen, yuvarlak hatlar yapan özelliği ile yelek tasarımı yapılmış, ehram kumaşı çalışmaya yön göstererek tasarımda değişik dokular yaratma imkanı vermiştir. Tasarımcı geleneksel kumaşın olanaklarını sonuna dek değerlendirmiş, bilinen kumaştan çok farklı bir görsellik sergilenmiştir. ${ }^{3}$

\section{Örnek:3}

Çalıştay kapsamında iki tasarımcı tarafından Siirt şal-şepik (gej) kumaşı, ayrı ayrı kullanılmıştır. Her iki tasarımcının hacim yaratma isteğine uygun cevap verdiği gözlemlenen dokuma, biri tasarımda dokusu deforme edilirken, diğerinde dokuya dikiş imkanları ile verilen hacimlendirmelerle güncel yaşamda kullanılabilecek yelek tasarımları yaratılmış ve hem kadın hem de erkekler tarafından kullanılabilecek güncel örnekler olarak sergilenmiştir. ${ }^{4}$ Aynı geleneksel kumaş; bu güncel tasarım nesneleri dışında, günümüzde Siirt olarak bildiğimiz şehrin geçmişteki isim ve mimarisinden esinlenerek "Üç Şehir" adı verilen sanatsal bir çalışma içinde kullanılmıştır. ${ }^{5}$

\section{Örnek:4}

Kastamonu ili Tosya ilçesindeki Tosya Kuşağ adı verilen kumaş da aynı projede, iki kişilik başka bir tekstil tasarımcısı ekip tarafından kullanılmıştır. Tasarım ekibi, ortak çalışmada "Kırk Parça" /kırk pare/kırk yama/ adı verdikleri tasarımlarında Kastamonu'nun şehir efsanelerinden biri olan "Kastın ne Moni" nin hikayesinden yola çıkarak yaratmışlardır. Tasarlanan yelek, dar dokuma kuşaktan kesilmiş, kırk ayrı dokuma parçanın birleşiminden oluşturulmuştur. Çok farklı amaçlarla kullanılan bu geleneksel dar dokuma kumaş, görselliği etkili bir kadın yeleği, olarak tasarlanmış ve fantezi bir kullanım için önerilmiştir. ${ }^{6}$

Tosya kuşağı yelek tasarımı yanında sanatsal bir üretim için de kullanılmıştır. Sanatsal çalışmanın yöreye bağlantılı öyküsü Cumhuriyet Devrimleri’ne dayanmaktadır. Kastamonu kökenli, Makedonyalı bir tasarımcı tarafından doğduğu topraklara ilişkin duygusal bir anlatımdan yola çıkan öykü için, doğal beyaz kuşak örneği özellikle seçilmiştir. ${ }^{7}$

Bölgenin yerel dokuması olan Tosya Kuşağı, bir ülkenin geleceğini ilgilendiren bir reform sembolü olan şapka ile birleştirilmiş; sanatçının eşitlik, özgürlük, insan hakları ve kadın mücadelesi konusundaki görüşlerini ifade etmek üzere, tasarlanan sanatsal obje için kullanılmıştır. ${ }^{8}$ Tüm bu kıl ve tiftik dokumalı tasarım ve sanatsal tekstil örnekleri 21 Mart 2016'da Cumhuriyet Müzesi'nde sergilenmiştir.

\footnotetext{
${ }^{3}$ Marmara Üniversitesi G.S.E. Öğrencisi, Balota, Büşra.

${ }^{4}$ Marmara Üniversitesi G.S.F. Öğrencisi, Şahin, Deniz, Akaydın, Ersel.

${ }^{5}$ Marmara Üniversitesi G.S.E. Öğrencisi, Gündüz, L. Gül.

${ }^{6}$ Marmara Üniversitesi G.S.E. Öğrencisi, Lyochi, Mashide, Gündüz, L. Gül.

71925 ylında Kastamonu'yu ilk kez ziyaret eden Mustafa Kemal Atatürk’ün başındaki beyaz kalın kenarlı şapkasını göstererek "bu serpuşa şapka derler" demesinden yola çıkarak ve devrimlerin insan eşitliğine dayanmaktadır.

${ }^{8}$ Marmara Üniversitesi G.S.E. Öğrencisi, Lyochi, Mashide.
} 


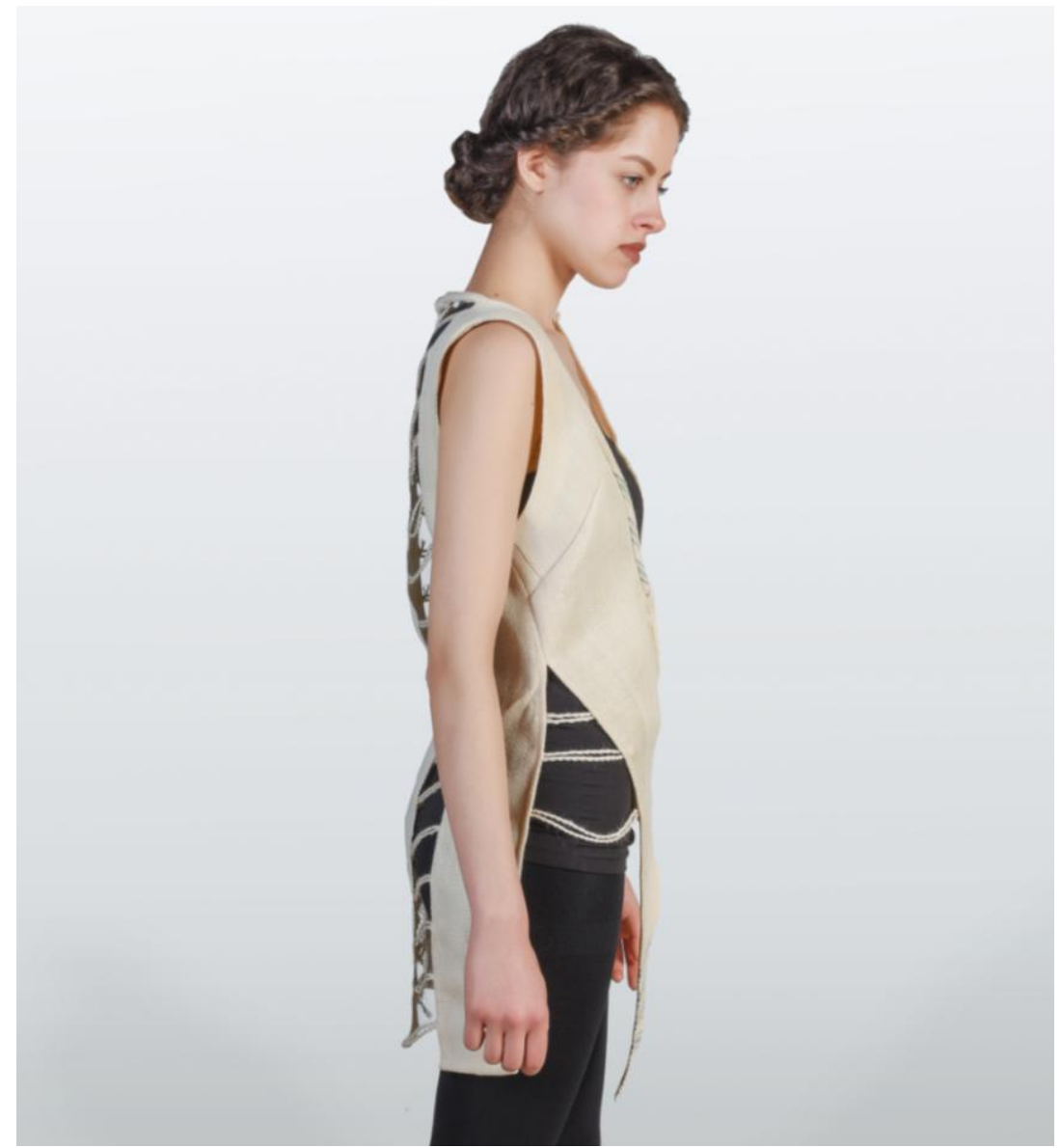

Fotoğraf: Mustafa Bilge Satkın

\section{SONUÇ}

$\mathrm{Bu}$ çalışma toplumların kültürel mirası olan geleneksel kıl ve tiftik dokumaların günümüz kullanım alanlarında yer alması için doğru öneriler yapmayı hedeflemiş ve çeşitli tasarım denemeleri ile araştırmayı desteklemiştir.

$\mathrm{Bu}$ süreçte geleneksel dokumanın temel özelliğinin öncelikle saptanmasını ve bu özelliği oluşturan ögenin öne çıkarılarak özelliklerinin değerlendirilmesi ön planda tutulmuştur. Yapılan değerlendirme sonucunda bölgelerdeki dokumanın kullanım amaçlarına göre farklılık göstermesinin yanı sıra bir takım fiziksel özelliklerinin de olduğu tespit edilmiştir. Örnek olarak kumaş eni ve desenlendirme şekillerinde farklılıklar görülmüştür.

Tiftik lifinin fiziki özellik ve görsel etkileri tasarımlarda belirleyici olarak yer almıştır. Lifin sertliği ve yıpranma güçlüğü değişik görsellikte yapılar için tasarımlarda etkili eleman olarak kullanılmıştır. Tiftik lifinin ince türü olan alt lifler, yine diri ve dökümlü özelliği ile giyside (yelek) belirgin bir biçimde özgünlük olarak ele alınmıştır. Sanatsal nesnede ise hacim vermede etkili bir özellik olarak kullanılmıştır. 


\section{KAYNAKÇA}

Akan, M. (2007). Yörüklerde taşımada kullanılan dokumalar. 38. ICANAS Bildiriler, Ankara, s. 21-44.

Atalayer, G. (1990). Yörük dokumaları. Kültür ve Sanat, (7), 65.

Atalayer, G. (1997). Anadolu'da yaşayan el dokumacılığı. Ev Tekstili, (13), 40-44.

Atalayer, G. (2014). Kültürel süreklilik ve Anadolu'da yaşayan dokumacıllk. Hometextile, (83), 76-78.

Çak, B. ve Küçük, M. (2005). Renkli tiftik keçilerinde transferin tipleri ile bazı tiftik özellikleri arasındaki ilişkiler. Yüzüncü Yıl Üniversitesi Veteriner Fakültesi Dergisi, 6(2), 61-64.

Deniz, B. (2007). Tekstil ürünlerini saklamada kullanılan halı ve düz dokumalar/ Carpets and flat weaves used for protecting textile products. Atatürk Üniversitesi Güzel Sanatlar Fakültesi Sanat Dergisi, (12), 1-13.

Erdem, N. (1988). Ege Bölgesi kıl keçi liflerinin bugünkü durumu ve değerlendirme imkanları üzerine bir araştırma. Tekstil \& Teknik Dergisi.

Gezer, E. (2005). Aydın ili Bozdoğan ilçesi kıl dokumacılığı. Yayınlanmamış Yüksek Lisans Tezi, A. Ü. Fen Bilimleri Enstitüsü, Ankara.

Harmancioğlu, M. (1974). Lif teknolojisi (yün ve deri ürünü diğer lifler). Bornova-İzmir: Ege Üniversitesi Matbaası.

Kademoğlu, O. (1974). Yörüklerde üç direkli karaçadır. 1. Uluslararası Türk Folkloru Semineri Bildirileri, Ankara, s. 296-304.

Kermen, O. (1981). Tekstil lifleri lifanalizi ve lif boyama tekniği. İstanbul: İstanbul Devlet Tatbiki Güzel Sanatlar Yüksek Okulu Yayını.

Özey, R. (1990). Olukbaşı, Kızılca ve Dutaağaç (Bozdoğan-Aydın) köylerinde kıl çadır dokumacılığı. Türk Dünyası Araştırma Dergisi, (68), 163-190.

Süpüren Mengüç, G. ve Özdil, N. (2014). Özel hayvansal lifler. Tekstil Teknolojileri Elektronik Dergisi, $8(2), 30-47$.

(y.y.) (2007). Yörüklerden günümüze gelen dokumalar: Heybeler, çuvallar, yüklükler. Ev Tekstili Dergisi, (57), 66-69.

\section{Sözlü Görüşmeler}

Ataner, Sevim. (2016). Bayburt, Kişisel görüşme, Temmuz.

Durak, Ayşe. (2015). Bursa Keles Halk Eğitim Merkezi dokuma ustası kişisel görüşme. Bursa\ Keles ,24 Ekim.

İnan, Nezahat. (2015). Siirt, Eruh Halk Eğitim Merkezi usta öğretici kişisel görüşme. İstanbul, 25 Kasım.

Öztaban, Dursun. (2013). Kişisel görüşme. Aydın\ Bozdoğan Olukbaşı Köyü, Kasım. 